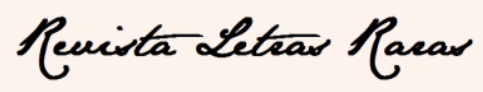

ISSN: 2317-2347 - v. 7, n. 2 (2018)

\title{
História de Ninguém ${ }^{1}$
}

Charles Dickens* $^{*}$

Ele vivia na beira de um rio corrente, largo e profundo, que sempre corria silenciosamente até um oceano vasto e desconhecido. O Rio fluía desde que o mundo é mundo. Tinha mudado seu curso algumas vezes e desembocado em novos canais, deixando os antigos caminhos secos e inférteis; mas sempre seguia seu fluxo, e sempre fluiria até quando o Tempo deixasse de existir. Contra sua forte e misteriosa correnteza, nada o ultrapassava. Nenhuma criatura viva, nem flor, nem folha, nem partícula de existência animada ou inanimada, jamais voltava desse desconhecido oceano. A correnteza do rio corria sem resistência em direção a ele; e nunca parava, tal qual as voltas da Terra ao redor do Sol.

Ele vivia em um lugar agitado e trabalhava muito duro para sobreviver. Não tinha esperança de algum dia ser rico o suficiente para viver sem trabalhar por um mês, mas ele estava conformado, DEUS sabe, de labutar com otimismo. Ele era de uma família imensa, na qual todos os filhos e filhas ganhavam seu pão de cada dia com trabalho diário, de dia à noite. Além desse destino, ele não tinha perspectiva, nem procurava uma.

Havia muito batuque, trombetas e disse-me-disse na vizinhança onde ele morava; mas ele não tinha nada a ver com isso. Tal estrondo e alvoroço vinham da família Mandachuva, dos incontáveis procedimentos dessa linhagem que ele tanto admirava. A

\footnotetext{
${ }^{1}$ A obra de Charles Dickens (1812-1870) está divulgada em domínio público e pode ser acessada em <http://www.dominiopublico.gov.br/pesquisa/ResultadoPesquisaObraForm.do> e em <http://www.freeshort-stories.org.uk/charles-dickens-free-short-stories.htm>.

* Traduzido por:

Sinara de Oliveira Branco, Doutora em Letras/Tradução (UFSC) e professora da Universidade Federal de Campina Grande (UFCG). Membro do Programa de Pós-Graduação em Linguagem e Ensino da UFCG, sinarabranco@gmail.com.

Marina Soares Duarte Silveira, graduanda Letras-Inglês na Universidade Federal de Campina Grande (UFCG), marina.silveirads@gmail.com.

Ana Beatriz Miranda Jorge, graduanda Letras-Inglês na Universidade Federal de Campina Grande (UFCG), beatrizjmiranda@gmail.com.
} 


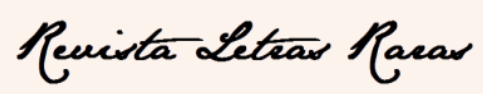

ISSN: $2317-2347$ - v. 7, n. 2 (2018)

família construía as estátuas mais estranhas feitas de ferro, mármore, bronze e latão bem em frente à sua casa; e escureciam a casa dele com imagens toscas de pernas e rabos de cavalos. Ele imaginava o que tudo aquilo significava, sorria de um jeito travado e bem humorado que tinha, e continuava seu duro trabalho.

A família Mandachuva (composta pelas pessoas mais pomposas e barulhentas do lugar) tinha prometido lhe ajudar com o trabalho de pensar por si mesmo, e de administrar ele e suas coisas. "De fato," dizia ele, "eu tenho pouco tempo em minhas mãos; e se vocês forem realmente bons a ponto de cuidar de mim, em troca do dinheiro que eu pague", porque a família Mandachuva não tinha domínio do dinheiro dele, "eu ficarei aliviado e muito agradecido, sabendo que vocês são mais entendidos." Daí o batuque, trombetas e disse-me-disse, e as feias imagens de cavalos pelas quais esperavam que ele se curvasse e venerasse.

"Eu não entendo nada disso," dizia ele, esfregando confusamente seu cenho franzido. "Mas isso TEM um significado, talvez, se eu pudesse descobrir."

"Significa," retrucava a família Mandachuva, suspeitando do que ele dizia, "honra e glória do mais alto para o mais alto mérito."

“Ahh!” dizia ele. E ficava feliz por ouvir aquilo.

Mas, quando ele olhava dentre as imagens de ferro, mármore, bronze e latão, ele não conseguia encontrar aquele camponês bastante digno de si, uma vez filho de um comerciante de lã de Warwickshire ${ }^{2}$, ou de qualquer outro camponês do tipo. Ele não conseguia encontrar nenhum dos homens, cujo saber socorreu a ele e as suas crianças de uma doença terrível e desfigurante, cuja ousadia tinha elevado seus antepassados da condição de servos, cuja sensata fantasia tinha aberto uma existência nova e superior aos mais humildes, cuja habilidade tinha preenchido o mundo do trabalhador com sonhos acumulados. Pelo contrário, ele encontrou outros de quem ele não sabia boas coisas, e ainda outros de quem muito mal sabia.

\footnotetext{
${ }^{2}$ Warwickshire é um condado no centro da Inglaterra. (N. T.)
} 


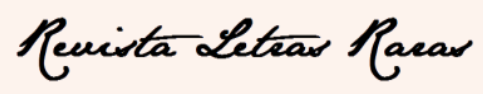

ISSN: 2317-2347 - v. 7, n. 2 (2018)

"Hmmmm!" dizia ele. "Eu não entendo bem isso."

Então, ele ia para casa e sentava ao lado da lareira para tirar isso de sua mente.

Agora, sua lareira era apenas cinzas, toda cercada por ruas escurecidas; mas era um lugar precioso para ele. As mãos de sua esposa eram calejadas de trabalho e ela era uma velha antes do tempo; mas ela era boa para ele. Suas crianças, atrofiadas no crescimento, deixavam vestígios de desnutrição; mas elas eram belas aos seus olhos. Acima de tudo, era um desejo do fundo da alma desse homem que as suas crianças fossem escolarizadas. "Se, às vezes, eu sou enganado," ele disse, "por falta de conhecimento, pelo menos, que elas sejam inteligentes e evitem meus erros. Se é difícil para eu colher os frutos do prazer e da instrução que estão nos livros, que seja mais fácil para elas."

Mas, a família Mandachuva começou a ter várias brigas familiares sobre o que era permitido ensinar às crianças desse homem. Algumas pessoas da família insistiam em uma coisa como primária e indispensável acima de todas outras coisas; e outras da família insistiam em outras coisas; daí a família Mandachuva, separada por facções, escreveu panfletos, realizou reuniões, fez acusações, orações e todos os tipos de discursos; apreendeu um ao outro em tribunais Leigos e Eclesiásticos; jogou sujo, trocou ameaças e fracassou pelos seus próprios ouvidos em uma incompreensível antipatia. Enquanto isso, esse homem, em sua breve noite, apossou-se da lareira, viu o demônio da Ignorância aparecer ali e tomar suas crianças para si. Ele viu sua filha ser pervertida em um pesado e devastador trabalho inferior; ele viu seu filho passar dos caminhos da baixa sensualidade para a brutalidade e o crime; ele viu a aurora da inteligência nos olhos de seus bebês mudar para astúcia e suspeita, a ponto de ele quase desejar que fossem idiotas.

"Eu continuo sem entender nada disso," disse ele; "mas eu acho que não está certo. Não, pelo céu nublado acima de mim, eu protesto contra isso como erro meu!"

Ficando calmo novamente (pois sua cólera era de curta duração e seu coração era bondoso), ele olhou para si mesmo em seus domingos e feriados e percebeu muita 


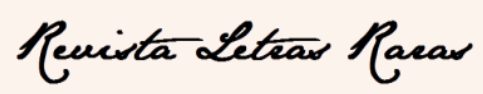

ISSN: $2317-2347$ - v. 7, n. 2 (2018)

monotonia e cansaço e também quanta bebedeira surgiu ali com toda a sua ruína. Assim, ele apelou para a família Mandachuva e disse, "Somos um povo trabalhador e eu tenho uma forte suspeita de que o povo trabalhador foi preparado para qualquer condição, de uma inteligência maior que a sua, como eu pobremente entendo, estar em necessidade de refresco e recreio mental. Veja o que acontece com a gente quando descansarmos sem isso. Venha! Me divirta inofensivamente! Me mostre algo, me dê uma saída!"

Mas, aqui, a família Mandachuva caiu em um estado de alvoroço extremamente ensurdecedor. Quando algumas vozes foram indistintamente ouvidas, propondo mostrar a ele as maravilhas do mundo, a grandeza da criação, as correntes mudanças do tempo, os trabalhos da natureza e as belezas da arte, para lhe mostrar essas coisas em qualquer momento de sua vida quando ele pudesse considerá-los, surgiu dentre os Mandachuva um berro e um delírio, um altar e uma petição, um vaguear e um memorizar, um xingamento e uma jogada suja, um vento estridente de questionamento parlamentar e uma resposta fraca, onde "eu não me atrevo" se tornou "eu me atreveria", que o pobre homem ficou horrorizado, olhando em volta.

"Será que eu provoquei tudo isso," disse ele, com as mãos em seus ouvidos assustados, "pelo que era um pedido inocente, que surgiu de fora da minha experiência familiar, e do conhecimento comum de todos os homens que escolhem abrir os olhos? Eu não compreendo nem sou compreendido. No que é que isso vai dar!"

Ele estava se curvando ao seu trabalho, constantemente se fazendo essa pergunta, quando começou a se espalhar a notícia de que uma doença pestilenta tinha se espalhado dentre os trabalhadores e estava matando aos montes. Saindo para se informar, ele logo soube que era verdade. Os doentes e os mortos estavam misturados nas casas próximas e contaminadas onde ele viu sua vida passar. O novo veneno estava espalhado no ar, sempre sombrio e nauseante. Os fortes e os fracos, os velhos e as crianças, o pai e a mãe, todos foram atingidos. 


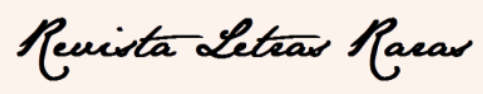

ISSN: 2317-2347 - v. 7, n. 2 (2018)

Que opções de fuga ele tinha? Ele permaneceu lá, onde estava, e viu aqueles que eram queridos morrerem. Um pregador gentil se aproximou dele, e teria feito algumas orações para acalmar seu coração, mas ele disse:

"Que proveito tem isso, missionário, de você vir até mim, um homem condenado a morar neste lugar podre, onde todo o sentido a mim concedido, para o meu prazer, se torna uma tormenta e cada minuto dos meus dias contados é a nova lama acrescentada à pilha na qual eu sou oprimido. Mas, me dê meu primeiro vislumbre do céu, por sua fresta de luz e ar; me dê água pura; me ajude a ser limpo; alivie esta atmosfera e vida pesada, em que nossos espíritos afundam e nos tornamos as criaturas indiferentes e insensíveis que vocês tanto veem; leve gentilmente os corpos dos que morrem entre a gente para fora da sala pequena onde crescemos para nos acostumarmos com a mudança terrível de que até mesmo a santidade não existe para nós; e, mestre, então vou ouvir, ninguém sabe melhor que você, o quanto foi disposto da parte Dele, cujos pensamentos estavam tanto com os pobres, e quem tinha tanta compaixão pela tristeza humana!"

Ele estava trabalhando de novo, solitário e triste, quando seu Mestre veio e ficou ao seu lado, vestido de preto. Ele também tinha sofrido muito. Sua jovem esposa, sua linda e boa jovem esposa estava morta; assim como o seu único filho.

"Mestre, é difícil suportar, eu sei, mas se sinta consolado. Eu te consolaria se eu pudesse.

O Mestre agradeceu de todo coração, mas disse, "Vocês trabalhadores! A calamidade começou entre vocês. Se tivessem vivido saudável e decentemente, eu não estaria viúvo e de luto como estou hoje."

"Mestre," lamentou o outro, mexendo a cabeça, "Eu comecei a entender um pouco, que todas as calamidades virão de nós, assim como esta última, e que nenhuma vai parar nas nossas portas pobres até estarmos unidos com essas famílias briguentas acolá para fazer as coisas que são certas. Não podemos viver saudáveis e decentemente, a não ser que aqueles que assumiram nos administrar forneçam os meios. Não podemos ser 


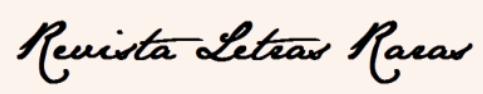

ISSN: 2317-2347 - v. 7, n. 2 (2018)

escolarizados, a não ser que nos ensinem; não podemos ser racionalmente divertidos, a não ser que nos divirtam; não podemos, porém, ter alguns deuses falsos criados por nós mesmos, enquanto eles põem tantos outros deles nos lugares públicos. As más consequências de uma escolarização falha, de negligência fatal, de restrição não natural e negação de prazeres humanos virão todas de nós, e nenhuma delas nos impedirá. Elas vão se espalhar para longe. Elas sempre se espalham; sempre se espalharam, assim como a doença. Enfim, acho que eu finalmente entendo o bastante."

Mas o Mestre disse de novo, "Vocês trabalhadores! Raramente ouvimos vocês, a não ser quando está relacionado com algum problema!”

"Mestre", ele disse, "Eu sou Ninguém, pouco provável de ser ouvido (nem muito esperado de ser ouvido, talvez) exceto quando há algum problema. Mas nunca começa comigo, e nunca pode terminar comigo. Assim como a Morte, isso vem e vai a partir de mim."

Havia tanto sentido no que ele dizia que a família Mandachuva, tomando conhecimento disso e se assustando por causa de sua desolação, resolveu se unir a ele para fazer as coisas que eram certas, em todos os momentos, assim como as coisas ditas eram associadas com a prevenção direta, humanamente falando, de outra doença. Mas, à medida que o medo ia embora, e assim foi, eles se recompuseram e não fizeram nada. Consequentemente, a praga apareceu novamente, de baixo de novo, e aumentou vingativamente, como antes, e levou vários arruaceiros. Mas nenhum homem dentre eles jamais admitiu, desde um grau menor, que ele tinha algo a ver com isso.

Então, Ninguém viveu e morreu da maneira mais antiga; e isto, resumindo, é a história de Ninguém.

Ele não tinha nome, você se pergunta? Talvez fosse Legion. Pouco importa seu nome. Vamos chamá-lo de Legion. 


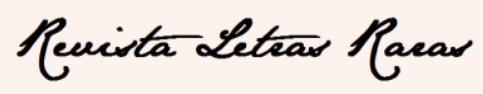

ISSN: 2317-2347 - v. 7, n. 2 (2018)

Se você já esteve alguma vez nas vilas Belgas próximas de $\mathrm{Waterloo}^{3}$, você terá visto, em alguma quieta igrejinha, um monumento erguido por companheiros confiáveis em homenagem à memória de Coronel A, Major B, Capitães C, D e E, Tenentes F e G, Estandartes H, I e J, sete oficiais não comissionados, e cento e trinta classificados e arquivados que executaram seus deveres no dia memorável. A história de Ninguém é a história das coisas classificadas e arquivadas da Terra. Elas suportam a comunhão de batalhas; elas têm sua parte na vitória; elas caem; elas não deixam nomes, exceto em massa. A marcha dos mais orgulhosos de nós nos leva para um caminho empoeirado que eles seguem. Olhem! Permitam que pensemos neles neste ano, na fogueira de Natal, e que não nos esqueçamos quando esta se apagar.

\section{REFERÊNCIA}

DICKENS, Charles. Nobody's Story. Adelaide: The University of Adelaide Library, 2014.

Recebimento: 06/05/2018

Aceite: $14 / 09 / 2018$

\footnotetext{
${ }^{3}$ Município localizado na província de Brabante, no norte da Bélgica. (N. T.)
} 